\title{
Chapter
}

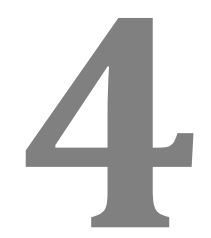

\section{CHARACTERIZATION OF DRUG-LOADED NANOPARTICLES}

Irina Kalashnikova ${ }^{1}$, Norah Albekairi' ${ }^{2}$, Sanaalarab Al-Enazy ${ }^{2}$, and Erik Rytting1,2,3*

${ }^{1}$ Department of Obstetrics \& Gynecology, University of Texas Medical Branch, Galveston, Texas, USA

${ }^{2}$ Department of Pharmacology \& Toxicology, University of Texas Medical Branch, Galveston, Texas, USA

${ }^{3}$ Center for Biomedical Engineering, University of Texas Medical Branch, Galveston, Texas, USA 


\section{Contents}

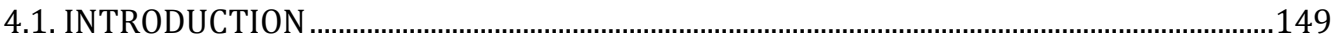

4.1.1. Polymeric nanoparticles .........................................................................................149

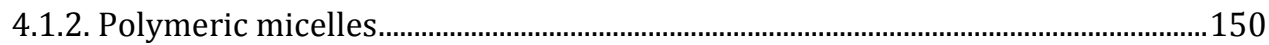

4.1.3. Dendrimers .............................................................................................................151

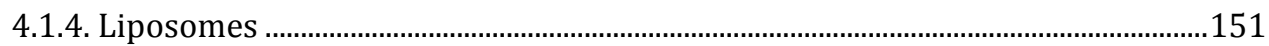

4.1.5. Solid lipid nanoparticles ...................................................................................151

4.1.6. Metal and metal oxide nanoparticles .................................................................152

4.2. NANOPARTICLE CHARACTERIZATION…………………………………………………....152

4.2.1. Particle size and shape .......................................................................................152

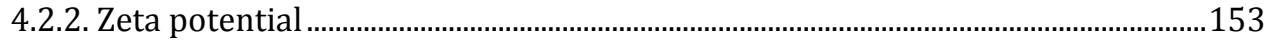

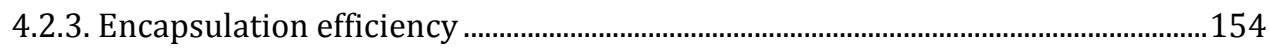

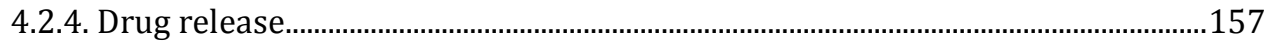

4.2.5. Time-resolved small-angle neutron scattering (TR-SANS) ..................................158

4.2.6. X-ray diffraction...................................................................................................

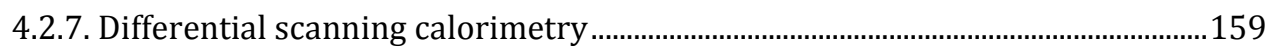

4.2.8. Fourier transform infrared spectroscopy (FTIR) .................................................159

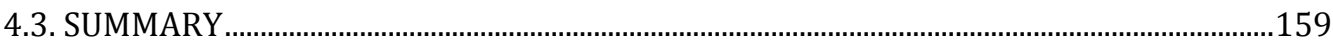

ACKNOWLEDGMENTS..................................................................................................................... 160

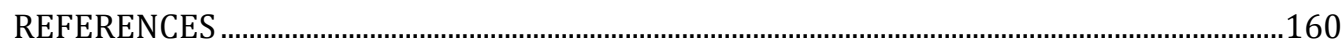




\subsection{INTRODUCTION}

Advantages of nanoparticles for drug delivery applications include drug targeting, controlled drug release, protection of therapeutic payload, and improved bioavailability [1]. In the development of drug-loaded nanoparticles, it is imperative that the nanoparticles are adequately characterized in terms of size, surface charge, encapsulation efficiency, and drug release. These characteristics will guide the scientist in the selection of an optimal nanoformulation to enhance drug delivery. Targeting ligands on the nanoparticle surfaces can promote cellular uptake and transport. These include peptides, small molecules, transferrin, and antibody fragments [2].

Several materials have been utilized for the development of drug-loaded nanoparticles, including polymeric nanoparticles, polymeric micelles, dendrimers, liposomes, and solid lipid nanoparticles [3]. Examples of these nanoparticle types will be reviewed, followed by definitions and equations related to typical steps for the characterization of drug-loaded nanoparticles. As this chapter encompasses a wide variety of nanoparticle types, readers are referred to specific citations for details regarding methods for the synthesis of each type of drug-loaded nanoparticle.

\subsubsection{Polymeric nanoparticles}

Table 1 lists a number of synthetic and natural polymers that have been utilized in the preparation of nanoparticles for drug delivery [4-9]. Methods for the preparation of nanoparticles from synthetic polymers include emulsionsolvent evaporation/extraction, nanoprecipitation, emulsification/solvent diffusion, salting out, dialysis, emulsion polymerization, spray drying, supercritical fluid technology, electrospraying, sonoprecipitation, and aerosol flow reactor methods $[4,6,8,10]$. Production of nanoparticles from natural polymers includes methods such as coacervation/precipitation, emulsification, emulsion cross-linking, spray drying, ionic gelation, emulsion-droplet coalescence, sieving, and a reverse micellar method [7,11]. The best nanoparticle synthesis method for drug encapsulation will depend on the desired particle characteristics, the type of polymer, and the physicochemical properties of the drug. 
Table 1. Examples of natural and synthetic polymers used in the development of drug-loaded nanoparticles

\begin{tabular}{cc}
\hline Natural Polymers & Synthetic Polymers \\
\hline Chitosan & Poly(caprolactone) \\
Gelatin & Polylactide, Polyglycolide \\
Sodium alginate & Poly(alkylcyanoacrylates) \\
Pullulan & Poly(ethyleneimine) \\
Starch & Poly(methylidene malonate) \\
Heparin & Polyanhydrides \\
Proteins & Poly(ortho esters) \\
& Poly(methyl methacrylate) \\
& Poly(vinyl alcohol) \\
\hline
\end{tabular}

A number of polymeric nanotherapeutics have proceeded to clinical trials, including CALAA-01 (a cyclodextrin and poly(ethylene glycol) (PEG) containing anticancer siRNA delivery platform) and BIND-014 (a poly(lacticco-glycolic acid) (PLGA)-PEG nanoplatform for the delivery of doxorubicin to treat prostate cancer) [12].

\subsubsection{Polymeric micelles}

Polymeric micelles can be produced by a direct dissolution method, an evaporation method, or nanoprecipitation/dialysis methods [13-16]. Several applications for drug-loaded polymeric micelles have been investigated, such as anticancer therapy, drug delivery to the brain, delivery of antifungal agents, and polynucleotide therapies [17-29]. Table 2 displays some anticancer polymeric micellar formulations that have progressed to clinical trials. The stability of polymeric micelles is dependent on the critical micelle concentration (CMC). If in vivo administration of the micelles results in dilution to below the CMC, this will lead to rapid dissociation of the micelles [30].

Table 2. Some polymeric micelle formulations that have been in clinical trials [19,31-41]

\begin{tabular}{ccc}
\hline Name & Drug & Polymeric composition \\
\hline NK105 & Paclitaxel & PEG-polyaspartate \\
\hline Genexol-PM & Paclitaxel & PEG-poly(D,L-lactic acid) \\
\hline NC6004 & Cisplatin & PEG-poly(glutamic acid) \\
\hline NK012 & SN-38 & PEG-poly(glutamic acid) \\
\hline SP1049C & Doxorubicin & Mixture of pluronic block copolymers L61 and F127 \\
\hline NK911 & Doxorubicin & PEG-polyaspartate \\
\hline
\end{tabular}




\subsubsection{Dendrimers}

Dendrimer materials commonly used in nanomedicine include poly(amidoamine) (PAMAM), poly(L-lysine), polyesters, poly(2,2-bis(hydroxymethyl)propionic acid), and amino-bis(methylenephosphonic acid) [42]. Dendrimers have been investigated as drug delivery systems for nonsteroidal anti-inflammatory drugs, antivirals, antimicrobials, anticancer agents, and antihypertensive drugs [43]. Synthetic approaches include divergent synthesis, convergent methods, click chemistry, solid-phase synthesis, self-assembly, and supramolecular synthesis [42-47]. Dendrimers can accommodate small molecules in their interiors, internal cavities, and surface channels. Drugs can be entrapped by chemical conjugation or by complexation through hydrophobic or electrostatic interactions [48]. The dendrimer structure (generation number, branch components, functionality of external termini and the core) will also affect drug entrapment.

\subsubsection{Liposomes}

Liposomes consist of phospholipid bilayers with amphiphilic properties and have been investigated as drug carriers since the 1960s. Hydrophobic agents can be solubilized within the phospholipid bilayers, and hydrophilic compounds can be entrapped within the aqueous core $[49,50]$. Liposomes are biocompatible and have been developed for the delivery of anticancer drugs, antibiotics, anti-inflammatory drugs, genes and proteins [49-54]. Liposome synthesis and control over particle size can be achieved by the thin film method, sonication, and extrusion [55-58]. Food and Drug Administration (FDA)-approved liposomal formulations include DepoCyt ${ }^{\circledR}$, AmBisome $^{\circledR}$, Doxil ${ }^{\circledR}$, Marqibo $^{\circledR}$, and DaunoXome ${ }^{\circledR}[59]$.

\subsubsection{Solid lipid nanoparticles}

Solid lipid nanoparticles have gained attention due to advantages such as increased drug stability, high drug payload, avoidance of organic solvents, and ease of preparation [60]. Solid lipid nanoparticles may enhance oral drug absorption, lymphatic uptake, and bioadhesion [61]. Dermal applications of solid lipid nanoparticles are possible due to improved skin hydration, viscoelasticity, and ultraviolet (UV) protection [62-64]. Solid lipid nanoparticles have been investigated for anticancer drug targeting, gene delivery, ocular delivery, pulmonary delivery, and brain targeting [65-68]. Methods for preparing solid lipid nanoparticles include high shear homogenization and ultrasound, high pressure homogenization, solvent emulsification/evaporation, solvent injection, and dilution of microemulsions or liquid crystalline phases [69-73]. 


\subsubsection{Metal and metal oxide nanoparticles}

The multiple properties of gold nanoparticles make them good candidates for theranostic applications. Depending on their size and shape, gold nanoparticles may absorb light in the near infrared region, thereby avoiding potential interference from tissue autofluorescence. Functionalization of gold nanoparticles is possible by means of gold-thiol covalent bonds, which allows for the conjugation of drug molecules to nanoparticle surfaces [74]. Release of the therapeutic cargo can be triggered by glutathione displacement. Gold-amine binding and other non-covalent strategies have also been explored. Gold nanoparticles may facilitate the delivery of antibiotics, anticancer agents, and oligonucleotides for gene therapy [74]. Mesoporous silica and zinc oxide nanoparticles have porous cores amenable to drug loading. Drug release from the pores could be triggered by $\mathrm{pH}$ changes or ultrasound [75]. Drugs may also be loaded onto metal oxide nanoparticle surfaces by electrostatic interactions between a positively-charged drug and a negatively-charged citrate surface on $\mathrm{Fe}_{3} \mathrm{O}_{4}$ magnetic nanoparticles, for example. Such particles could be directed to a diseased site by an external magnetic field [75].

\subsection{NANOPARTICLE CHARACTERIZATION}

\subsubsection{Particle size and shape}

In vitro and in vivo studies have shown that the interactions of nanoparticles with cells are correlated with particle size, shape, and surface characteristics [76-82]. It has been demonstrated that the cellular uptake of nanoparticles is size-dependent, with smaller particles being taken up more easily than larger particles [83]. Nanoparticles with dimensions between $250 \mathrm{~nm}$ and $3 \mu \mathrm{m}$ can be internalized within cells in vitro via phagocytosis and micropinocytosis. Nanoparticles smaller than $200 \mathrm{~nm}$, on the other hand, are more likely to involve other cellular uptake routes, such as clathrin- or caveolin-mediated endocytosis, independent endocytosis mechanisms, or passive transport $[76,82]$. Nevertheless, the internalization pathway may not adhere to these typical size guidelines if there are specific ligands on the nanoparticle surface $[76,84]$. The enhanced permeability and retention effect can be observed with nanoparticles with diameters ranging from 40-400 nm [76]. Particle size has been shown to affect the circulation time of liposomes [85]. Likewise, the circulation time of dendrimers depends on their size, as only dendrimers with a low generation number (G5 or less) and a hydrodynamic radius less than $3.5 \mathrm{~nm}$ are likely to be eliminated into the urine [86].

Nanoparticle shape can influence intracellular nanomaterial trafficking. Hexagonal shapes were shown to be retained in the cytoplasm, whereas rod-like particles could move towards the nucleus by microtubules [80]. The 
circulation time of elliptical discs has been shown to be longer than that of spherical particles, and differences in cellular internalization have been observed for cylinders, cubes, and particles of varying rigidity $[4,79,80,82,87]$.

Particle size and shape can be examined by electron microscopy or atomic force microscopy. With scanning electron microscopy (SEM), particles are coated with a thin layer of gold or platinum. However, the particles may shrink during the drying step, causing an under-estimation of actual particle diameters [88]. Since the individual sizes of a large number of nanoparticles must be tallied to determine average size and polydispersity index (PDI), it is usually more convenient to measure the particle size of nanoparticles in a liquid suspension by dynamic light scattering (also known as photon correlation spectroscopy). Nevertheless, it is still wise to confirm light scattering data by a microscopic method [88]. With light scattering, the Brownian motion of particles is related to particle size (small particles move faster than larger particles), and when the temperature and viscosity of the liquid are known, the hydrodynamic diameter can be determined using the Stokes-Einstein equation [89]. Particle size is usually reported as the Z-average diameter (also referred to as the cumulants mean). The standard deviation from multiple measurements should also be reported. Characterization of particle size is incomplete without the PDI, which describes the width of the particle size distribution. PDI values will range between 0 and 1 . If the majority of particles are the same size, the PDI will be close to zero. On the other hand, a sample containing a diverse mixture of particle sizes will have a larger PDI value. PDI values less than 0.40 can be deemed acceptable [90], PDI values less than 0.25 are favorable, and values under 0.10 are excellent.

\subsubsection{Zeta potential}

Surface charge can also affect nanoparticle biodistribution, opsonization, and toxicity [81]. Typically, larger and negatively charged nanoparticles exhibit less toxicity compared to smaller and positively charged polymeric particles [81]. Surface properties (such as charge and coating) are more likely to affect cellular internalization pathways than polymer type [77,78]. Negatively charged liposomes can have prolonged circulation times compared to neutral liposomes, which may be more readily recognized by macrophages and cleared from the body [91]. A number of surface coatings can prevent nanoparticle aggregation and opsonization, improve cellular uptake, increase wettability, and affect degradation rates. Examples of such nanoparticle surface coatings include poly(vinylpyrrolidone), PEG, dextran, chitosan, pullulan, sodium oleate, dodecylamine, polysorbate 80 , poloxamer 188 , poly(vinyl alcohol), poly(2methyl-2-oxazoline), poly(sulfobetaine methacrylate), and $\alpha$-tocopherol PEG-1000 succinate $[6,79,80]$.

The zeta potential $(\zeta)$ of a particle is a quantitative measure of its surface charge, and the value is typically reported in units of $\mathrm{mV}$. This is an important 
parameter with regards to the stability of a nanosuspension. If the absolute value of $\zeta$ of nanoparticles in suspension is less than $10 \mathrm{mV}$ (in other words, if $\zeta$ is less than $+10 \mathrm{mV}$ or greater than $-10 \mathrm{mV}$ ), then the nanoparticles are more likely to aggregate [92]. Due to the relatively neutral surface charge when $\zeta$ is close to zero, there is insufficient charge repulsion to prevent aggregation. On the other hand, if $\zeta$ is sufficiently positive or negative (e.g., $|\zeta|>25 \mathrm{mV})$, then charge repulsion of individual particles with similar charge will make aggregation less likely, leading to a more stable nanosuspension [93]. It is important to note that the numeric examples of 10 or $25 \mathrm{mV}$ mentioned in this paragraph are only guidelines that will not apply to every nanomaterial; stability will also depend on surface coatings. For example, nanoparticles coated with PEG may have $|\zeta|<10 \mathrm{mV}$ but still be stable [94]. $\zeta$ can be determined by laser Doppler velocimetry. When an electrical field is applied, the nanoparticles move towards the electrode of opposite charge. The quantification of this movement - referred to as electrophoretic mobility permits the determination of $\zeta$ through the Henry equation when the dielectric constant and the viscosity are known [95].

\subsubsection{Encapsulation efficiency}

The encapsulation efficiency of a nanoparticle formulation is defined as the fraction of the amount of drug used in the nanoparticle preparation process that was actually encapsulated within the nanoparticles. It is most often calculated indirectly by determining the amount of free drug that was not encapsulated, as described with the following equation [96]:

Encapsulation efficiency

$$
=\frac{\text { mass of drug added to the nanoparticles }- \text { mass of free drug }}{\text { mass of drug added to the nanoparticles }}
$$

Encapsulation efficiency is often presented as a percentage, in which case the fraction on the right side of the equation would be multiplied by $100 \%$. The determination of encapsulation efficiency requires separation of the nanoparticles from the surrounding medium in order to analyze the concentration of free, unencapsulated drug present in the aqueous nanosuspension. This can be achieved by high-speed centrifugation or by filtration. Caution is necessary in both cases. For instance, if high-speed centrifugation is applied to obtain a pellet of nanoparticles and a particle-free supernatant, care must be taken to ensure that handling of the samples does not cause any resuspension of nanoparticles into the supernatant prior to its analysis. In addition, one must ensure that the centrifugation was sufficient to collect all of the nanoparticles. The smaller the particles, the more difficult this may be. A simple method to check whether the supernatant is free of nanoparticles is to make a particle size measurement of the supernatant by dynamic light scattering. If the measurement provides particle diameter results, the centrifugation was not adequate. On the other hand, if the result 
matches the measurement of pure water (which may result in an instrumental error or warning), one can be confident that the supernatant is free of particles. In our laboratory, centrifugation at $110,000 \times g$ has been deemed successful for this purpose. If one uses filtration to separate the nanoparticles from the surrounding medium, care must first be taken to ensure that the filter membrane does in fact restrict the passage of nanoparticles into the filtrate. (This can be checked by dynamic light scattering as just described.) In addition, control experiments must be performed to determine whether the encapsulated drug itself binds to the filter membrane. If so, corrections will be necessary to account for such binding. The concentration of free, unencapsulated drug in the nanosuspension (quantified in the supernatant or filtrate) is usually determined by a validated high performance liquid chromatography (HPLC) method.

Additional definitions applicable to the discussion of encapsulation efficiency include theoretical drug loading and actual drug loading. The theoretical drug loading indicates the percentage of total nanoparticle mass that is drug, assuming $100 \%$ encapsulation efficiency. The theoretical drug loading thus represents the amount of drug introduced to the nanoparticle formulation. The actual drug loading is the actual percentage of drug mass contained within the nanoparticles once they have been formed and the encapsulation efficiency has been determined. It is important to note that although the actual drug loading can be approximated by the product of encapsulation efficiency $\times$ theoretical drug loading, this is only an approximation. The exact calculation of actual drug loading must take into account the fact that the total nanoparticle mass (e.g., drug mass plus polymer mass) is reduced by the amount of unencapsulated drug. Table 3 illustrates these points with several examples.

Table 3. Examples of the relationships between theoretical drug loading, actual drug loading, and encapsulation efficiency based on a simple nanoparticle formulation comprised of a single polymer and a single drug without additional excipients or stabilizers. In these examples, it is assumed that the entire polymer mass is recovered as nanoparticles.

\begin{tabular}{cccccccc}
\hline $\begin{array}{c}\text { Polymer Mass of } \\
\text { mass } \\
\text { added }\end{array}$ & $\begin{array}{c}\text { Theoretical } \\
\text { added }\end{array}$ & $\begin{array}{c}\text { Unencapsulated } \\
\text { drug }\end{array}$ & drug mass & $\begin{array}{c}\text { Actual } \\
\text { mass of } \\
\text { drug } \\
\text { encapsulated }\end{array}$ & $\begin{array}{c}\text { Actual } \\
\text { drug } \\
\text { loading }\end{array}$ & $\begin{array}{c}\text { Encapsulation Ratio (actual } \\
\text { efficiency }\end{array}$ & $\begin{array}{c}\text { Rag loading } \\
\text { drug } \\
\text { /theoretical } \\
\text { drug loading }\end{array}$ \\
\hline $99 \mathrm{mg}$ & $1 \mathrm{mg}$ & $1 \%$ & $0.2 \mathrm{mg}$ & $0.8 \mathrm{mg}$ & $0.80 \%$ & $80 \%$ & 0.802 \\
\hline $95 \mathrm{mg}$ & $5 \mathrm{mg}$ & $5 \%$ & $1 \mathrm{mg}$ & $4 \mathrm{mg}$ & $4.04 \%$ & $80 \%$ & 0.808 \\
\hline $90 \mathrm{mg}$ & $10 \mathrm{mg}$ & $10 \%$ & $1 \mathrm{mg}$ & $9 \mathrm{mg}$ & $9.09 \%$ & $90 \%$ & 0.909 \\
\hline $90 \mathrm{mg}$ & $10 \mathrm{mg}$ & $10 \%$ & $2 \mathrm{mg}$ & $8 \mathrm{mg}$ & $8.16 \%$ & $80 \%$ & 0.816 \\
\hline $90 \mathrm{mg}$ & $10 \mathrm{mg}$ & $10 \%$ & $3 \mathrm{mg}$ & $7 \mathrm{mg}$ & $7.22 \%$ & $70 \%$ & 0.722 \\
\hline $90 \mathrm{mg}$ & $10 \mathrm{mg}$ & $10 \%$ & $4 \mathrm{mg}$ & $6 \mathrm{mg}$ & $6.25 \%$ & $60 \%$ & 0.625 \\
\hline $90 \mathrm{mg}$ & $10 \mathrm{mg}$ & $10 \%$ & $5 \mathrm{mg}$ & $5 \mathrm{mg}$ & $5.26 \%$ & $50 \%$ & 0.526 \\
\hline $80 \mathrm{mg}$ & $20 \mathrm{mg}$ & $20 \%$ & $4 \mathrm{mg}$ & $16 \mathrm{mg}$ & $16.67 \%$ & $80 \%$ & 0.833 \\
\hline
\end{tabular}


The question is sometimes raised as to how many drug molecules are encapsulated within a single nanoparticle. To illustrate this point, we will use an example of drug-loaded polymeric (PEGylated PLGA) nanoparticles recently formulated in our laboratory. The particle size was approximately $100 \mathrm{~nm}$, the theoretical drug loading was $10 \%$, the encapsulation efficiency was $95 \%$, and the PDI was less than 0.25. For simplicity, we will assume a uniform particle size of $100 \mathrm{~nm}(\mathrm{PDI}=0)$, that the particles are spherical, and that the nanoparticle density is $1.33 \mathrm{~g} \mathrm{~cm}^{-3}$ (the density of PEG is $1.2 \mathrm{~g} \mathrm{~cm}^{-3}$ [97], the density of PLGA is $1.34 \mathrm{~g} \mathrm{~cm}^{-3}$ [98], and the density of the drug was approximately $2 \%$ greater than the density of PLGA). In a sample of nanosuspension containing $20 \mu \mathrm{g}$ of nanoparticles, the number of nanoparticles $\left(N_{\mathrm{NP}}\right)$ is given by the equation $N_{\mathrm{NP}}=\frac{W \cdot 6}{\rho \cdot \pi \cdot d^{3}}$, where $W$ is the nanoparticle mass in the sample, and $\rho$ is the density of a single nanoparticle. In this example, $N_{\mathrm{NP}}=2.87 \times 10^{10}$ particles. The mass of a single nanoparticle $\left(\right.$ mass $\left._{\mathrm{NP}}\right)$ is calculated as $\operatorname{mass}_{\mathrm{NP}}=\frac{W}{N_{\mathrm{NP}}}$, or in this case, $6.96 \times 10^{-10} \mu \mathrm{g}$. Since the encapsulation efficiency was $95 \%$, the actual drug loading is $9.548 \%$, so the mass of drug in a single nanoparticle (mass drug$_{\text {) }}$ is given by the product of the actual drug loading $\times$ mass $_{\mathrm{NP}}$, which in this example is equal to $6.65 \times 10^{-11} \mu \mathrm{g}$. Assuming a drug molecular weight (MW) of $500 \mathrm{Da}$, the number of moles of the drug in a single nanoparticle $\left(n_{\text {drug }}\right)$ is calculated as $n_{\text {drug }}=\frac{\text { mass }_{\text {drug }}}{\mathrm{MW}}$. In this example, a single nanoparticle contains $1.33 \times 10^{-10} \mathrm{nmol}$ of drug. Finally, the number of drug molecules encapsulated in a single nanoparticle is calculated as the product of $n_{\text {drug }} \times N_{\mathrm{A}}$ (Avogadro's number, $6.022 \times 10^{23}$ ), which in this example is approximately 80,000 . Although at first glance this might seem like a large number, it is important to consider the capacity of a three-dimensional spherical nanoparticle. A drug molecule with MW of 500 Da might have a molecular diameter in the range of $10-15 \AA$ (1-1.5 nm). To simplify the discussion, we will assign the diameter of the drug molecule to be $1 \mathrm{~nm}(10 \AA)$. As mentioned above for this example, the diameter of a single nanoparticle is $100 \mathrm{~nm}$. One might initially express a twodimensional reaction and state that only 100 drug molecules could possibly fit within this diameter. However, a $100 \mathrm{~nm}$ nanoparticle loaded with $1 \mathrm{~nm}$ drug molecules is not the same as a $100 \mathrm{~cm}$ bookshelf holding 100 books having a thickness of $1 \mathrm{~cm}$ each. Rather than picturing a bookshelf that is $100 \mathrm{~cm}$ wide, imagine instead a football stadium surrounding a field that is $100 \mathrm{~m}$ long. Continuing this analogy, assume that each spectator at the stadium needs $1 \mathrm{~m}$ of sitting space. A single sphere with a diameter of $100 \mathrm{~m}$ would take up an enormous amount of space in the center of a soccer field (which is approximately $100 \mathrm{~m}$ long and $70 \mathrm{~m}$ wide). Considering that the sphere's height would also extend $100 \mathrm{~m}$ upwards, it should not be so difficult now to imagine that 80,000 spectators in the stands might fit within $10 \%$ of the space of such a sphere. (A sphere with a diameter of $100 \mathrm{~nm}$ has a volume that is 1 million times greater than the volume of a sphere with a diameter of $1 \mathrm{~nm}$.) 


\subsubsection{Drug release}

An encapsulated drug must be released from the nanoparticle in order to exert its pharmacologic effects. Drug release kinetics are greatly influenced by the nature of the drug, nanomaterial composition, and the localization of the drug within the nanoparticles (i.e., whether the drug is encapsulated within the nanoparticle matrix, adsorbed to the nanoparticle surface, or covalently linked to the particle) $[6,99]$. Some nanoparticle formulations will display gradual or controlled release properties, which will offer a number of advantages with regards to dosing frequency. Mechanisms of drug release from within nanoparticles include diffusion, polymer degradation, and stimuli-responsive elements. Stimuli-responsive nanoparticles can increase the amount of drug released in response to either an endogenous or an external change in temperature, $\mathrm{pH}$, light, polarity, redox potential, ionic strength, enzymes, ultrasound, electromagnetic radiation, chemical or biochemical agents, and oxidative stress [47,99-103]. For polymeric nanoparticles, smaller particles are generally more prone to exhibit an initial burst release in comparison to larger particles; on the other hand, larger particles tend to exhibit a faster degradation rate in vivo $[6,84,104]$. Polymer degradation depends on location within the body, nanoparticle size and shape, and the MW of the polymeric matrix $[7,104]$. High MW polymers are more likely to degrade more slowly than low MW polymers [105].

Drug release kinetics are typically determined in a well-stirred physiologically relevant medium, such as phosphate buffered saline at pH 7.4 and at $37^{\circ} \mathrm{C}$. Sink conditions must be maintained, which means that the volume of medium used must be sufficient so that at the point at which $100 \%$ of drug release has occurred, the final concentration of the drug in the medium must not exceed $20 \%$ of the saturated concentration of the drug in that medium [106]. At time zero, the nanoparticles are added to the medium and samples of the medium are taken at specified time points for the duration of the study. A release study could last hours to weeks, depending on the kinetics of drug release for the nanoformulation in question. An initial sample should be taken at time zero (or, practically speaking, a few seconds after the nanoparticles have been added to the medium). At time zero, the percent of drug release should match closely with the percentage of unencapsulated free drug from the determination of encapsulation efficiency. Initial burst release is usually characterized at the 30- or 60-min time point (unless the kinetics of release are gradual over several weeks, in which case the sample after 1 day might serve as a more appropriate measure of burst release). Individual samples from the release study can be processed as described above for the determination of encapsulation efficiency; i.e., at each time point, the nanoparticles will be separated by high-speed centrifugation or filtration. The supernatant or filtrate will then be quantified by a validated HPLC method (or another suitable method applicable to the drug of interest) to determine the concentration of drug released from the nanoparticles at each time point. Alternatively, dialysis 
bags can be used to study drug release. In this case, the nanoparticle suspension will be mixed with release medium when it is placed inside dialysis tubing or a floating dialysis device that has a suitable pore size to prevent the nanoparticles from escaping the dialysis tubing or device, but which permits the released drug molecules to pass through the pores to be sampled from the external medium at the designated time points. Dialysis tubing pore sizes are often defined using molecular weight cutoffs (MWCO). As an example, a 12-14 kDa MWCO corresponds to a pore size of $2.4 \mathrm{~nm}$ [107]. Drug release data are often fit to a descriptive model. One of the most common is the Higuchi model, which relates the fraction of drug released to the square root of time, as indicated by the following equation: $\frac{M_{\mathrm{t}}}{M_{\infty}}=K \sqrt{t}$, where $M_{\mathrm{t}}$ is the mass of drug released at time $t, M_{\infty}$ is the total cumulative mass of drug released at infinite time, and the constant $K$ depends on experimental variables [108].

\subsubsection{Time-resolved small-angle neutron scattering (TR-SANS)}

Time-resolved small-angle neutron scattering can be considered an effective method to study the size, structure, development, and morphological changes of lipid/surfactant-based constructs, such as liposomes, micelles, and nanoparticle dispersions [109]. For example, TR-SANS was utilized to explore the effect of charge density, salinity, and temperature on the morphology of unilamellar vesicles (ULVs) $[110,111]$. Moreover, the TR-SANS technique provides data regarding coalescence, growth, and transformation of lipid vesicles. The kinetics of cylinder-to-sphere morphological transition have been studied in the block copolymer micelle system [112]. This technique can examine alterations in rigidity and the influence of nanomaterials on structural changes in biological systems [112].

\subsubsection{X-ray diffraction}

X-ray diffraction (XRD) is used to characterize crystallinity, crystal and molecular structure variations, non-crystalline periodicity and size, nanoformulation orientation (crystalline/amorphous), polymorphisms, and phase transitions $[113,114]$. XRD is a non-destructive technique that can examine the state of encapsulated drug [115]. Optimally, successfully encapsulated drug will be in an amorphous state, evenly distributed within the nanoparticles. Nanoparticle size can be calculated using the Debye-Scherrer equation: $d=0.89 \lambda / \beta \cos \theta$, where 0.89 is Scherrer's constant, $\lambda$ is the X-ray wavelength, $\theta$ is the Bragg diffraction angle, and $\beta$ is the full width at half-maximum of the diffraction peak corresponding to the plane $[116,117]$. Bragg's Law is applied to value of the interplanar spacing between the atoms $(d): 2 d \sin \theta=n \lambda$, where $n$ is a positive integer and $\lambda$ is the wavelength of incident wave. The dislocation of crystallographic defects within a crystal structure (dislocation density, $\delta$ ) can be determined using the expression: 
$\delta=15 \beta \cos \theta / 4 a D$, where $\theta$ is Bragg's diffraction angle, $a$ is the lattice constant and $D$ is the crystallite size [117].

\subsubsection{Differential scanning calorimetry}

Differential scanning calorimetry (DSC) can be used to quantify and investigate the following: solid and amorphous phases of nanomaterial and payload, percent crystallinity of the sample, polymorphic transitions, drug loading efficacy, conformational changes, self-assembly behavior, and stability $[118,119]$. Thermograms are typically recorded at a scanning rate of $5-10{ }^{\circ} \mathrm{C} \mathrm{min}-1$ from $25-250{ }^{\circ} \mathrm{C}$ under nitrogen flow (30 mL min-1) [113, 120-122]. DSC analysis should usually be performed for each component of the drug delivery system [113,118,120-123]. The disappearance of the melting peak of the loaded drug or bioactive agent indicates its encapsulation into the nanoparticles $[113,122]$. The presence of a drug's peak on the thermogram may indicate the physical adsorption of the drug on the nanoparticle's surface [118]. Decoration of a nanoparticle's surface via brushing, grafting, coating and covalent coupling of specific ligands can be confirmed and characterized by this technique as well $[113,118,120,121]$. The stability of drug-loaded nanoformulations can be verified by comparing thermograms obtained immediately after its fabrication to thermograms after long-term storage [96].

\subsubsection{Fourier transform infrared spectroscopy (FTIR)}

Chemical composition, the presence of chemical bonds, and functional groups within or on the surface of nanoparticles can be determined by Fourier transform infrared spectroscopy (FTIR). FTIR as well as XRD can characterize the interactions between a drug and the nanoparticle matrix [124]. Infrared-spectroscopic nanoimaging with a thermal source (nano-FTIR) offers improved capabilities in the application of conventional FTIR to nanomaterial characterization [125]. With nano-FTIR, the chemical identification of nanomaterials, quantitative assessment of mobility in doped nanostructures, and the presence of any contaminants are possible in ultra-small quantities and at ultra-high resolution [126].

\subsection{SUMMARY}

The prospects for nanomedicine to improve human health are tremendous. A number of drug-loaded nanoparticle formulations have already reached the market, many are currently in clinical trials, and new developments will continue to advance the field. As scientists work to create future formulations, the characterization of drug-loaded nanoparticles will guide the optimization of new products. When in vitro characterization data are confirmed in vivo [127], the team gains confidence to apply the benefits of 
nanotechnology to improve the pharmacokinetics, pharmacodynamics, and safety profile of medications.

\section{ACKNOWLEDGMENTS}

The authors are grateful for research support provided through the John Sealy Memorial Endowment Fund for Biomedical Research, Citizens United for Research in Epilepsy, the Saudi Cultural Mission, and the Institute for Translational Sciences at the University of Texas Medical Branch, which is supported in part by a Clinical and Translational Science Award (UL1TR000071) from the National Center for Advancing Translational Sciences, National Institutes of Health.

\section{REFERENCES}

1. E. Rytting, J. Nguyen, X. Wang, T. Kissel. Expert Opin. Drug Deliv. 5 (2008) 629-639.

2. $\quad$ R.A. Petros, J.M. DeSimone. Nat. Rev. Drug Discov. 9 (2010) 615-627.

3. M.S. Muthu, S. Singh. Nanomedicine. 4 (2009) 105-118.

4. B.V.N. Nagavarma, H.K. Yadav, A. Ayaz, L.S. Vasudha, H.G. Shivakumar. Asian J. Pharm. Clin. Res. 5 (2012) 16-23.

5. M.R. Shaik, M. Korsapati, D. Panati. Int. J. Pharma Sci. 2 (2012) 112-116.

6. A. Mahapatro, D.K. Singh. J. Nanobiotechnol. 9 (2011) 1-11.

7. M. Dash, F. Chiellini, R.M. Ottenbrite, E. Chiellini. Prog. Polym. Sci. 36 (2011) 981-1014.

8. Y. Pathak, D. Thassu, Drug delivery nanoparticles formulation and characterization, Informa Healthcare, New York, USA, 2009, pp. 1-416.

9. S.K. Nitta, K. Numata. Int. J. Mol. Sci. 14 (2013) 1629-1654.

10. H.-K. Chan, P.C.L. Kwok. Adv. Drug Deliv. Rev. 63 (2011) 406-416.

11. J. Allouche, Nanomaterials: A Danger or a Promise?, Springer, New York, USA, 2013, pp. 27-74.

12. J. Shi, Z. Xiao, N. Kamaly, O.C. Farokhzad. Accounts Chem. Res. 44 (2011) 1123-1134.

13. [V.Y. Alakhov, E.Y. Moskaleva, E.V. Batrakova, A.V. Kabanov. Bioconjugate Chem. 7 (1996) 209-216.

14. X.-Y. Lu, D.-C. Wu, Z.-J. Li, G.-Q. Chen. Prog. Mol. Biol. Transl. Sci. 104 (2010) 299-323.

15. M. Yokoyama, G.S. Kwon, T. Okano, Y. Sakurai, T. Seto, K. Kataoka. Bioconjugate Chem. 3 (1992) 295-301.

16. V. Andrieu, H. Fessi, M. Dubrasquet, J.-P. Devissaguet, F. Puisieux, S. Benita. Drug Des. Deliv. 4 (1989) 295-302.

17. V.P. Torchilin. Pharm. Res. 24 (2007) 1-16.

18. Y. Bae, N. Nishiyama, S. Fukushima, H. Koyama, M. Yasuhiro, K. Kataoka. Bioconjugate Chem. 16 (2005) 122-130.

19. J.-L. Lee, J.-H. Ahn, S.H. Park, H.Y. Lim, J.H. Kwon, S. Ahn, C. Song, J.H. Hong, C.S. Kim, H. Ahn. Investig. New Drugs. 30 (2012) 1984-1990. 
20. E.V. Batrakova, Y. Zhang, Y. Li, S. Li, S.V. Vinogradov, Y. Persidsky, V.Y. Alakhov, D.W. Miller, A.V. Kabanov. Pharm. Res. 21 (2004) 1993-2000.

21. E.V. Batrakova, D.W. Miller, S. Li, V.Y. Alakhov, A.V. Kabanov, W.F. Elmquist. J. Pharmacol. Exp. Ther. 296 (2001) 551-557.

22. A.V. Kabanov, E.V. Batrakova, D.W. Miller. Adv. Drug Deliv. Rev. 55 (2003) 151-164.

23. A.V. Kabanov, E.V. Batrakova. Curr. Pharm. Des. 10 (2004) 1355-1363.

24. G.S. Kwon. Crit. Rev. Ther. Drug Carr. Syst. 20 (2003) 357-403.

25. M.L. Adams, D.R. Andes, G.S. Kwon. Biomacromolecules. 4 (2003) 750-757.

26. S.R. Croy, G.S. Kwon. J. Control. Release. 95 (2004) 161-171.

27. D. Oupicky, M. Ogris, K.A. Howard, P.R. Dash, K. Ulbrich, L.W. Seymour. Mol. Ther. 5 (2002) 463-472.

28. M. Harada-Shiba, K. Yamauchi, A. Harada, I. Takamisawa, K. Shimokado, K. Kataoka. Gene Ther. 9 (2002) 407-414.

29. A.I. Belenkov, V.Y. Alakhov, A.V. Kabanov, S.V. Vinogradov, L.C. Panasci, B.P. Monia, T.Y.K. Chow. Gene Ther. 11 (2004) 1665-1672.

30. $\quad$ S.C. Owen, D.P. Chan, M.S. Shoichet. Nano Today. 7 (2012) 53-65.

31. T. Hamaguchi, Y. Matsumura, M. Suzuki, K. Shimizu, R. Goda, I. Nakamura, I. Nakatomi, M. Yokoyama, K. Kataoka, T. Kakizoe. Br. J. Cancer 92 (2005) 1240-1246.

32. S.C. Kim, D.W. Kim, Y.H. Shim, J.S. Bang, H.S. Oh, S.W. Kim, M.H. Seo. J. Control. Release. 72 (2001) 191-202.

33. D.-W. Kim, S.-Y. Kim, H.-K. Kim, S.-W. Kim, S.W. Shin, J.S. Kim, K. Park, M.Y. Lee, D.S. Heo. Ann. Oncol. 18 (2007) 2009-2014.

34. M. Yokoyama, T. Okano, Y. Sakurai, S. Suwa, K. Kataoka. J. Control. Release 39 (1996) 351-356.

35. H. Uchino, Y. Matsumura, T. Negishi, F. Koizumi, T. Hayashi, T. Honda, N. Nishiyama, K. Kataoka, S. Naito, T. Kakizoe. Br. J. Cancer 93 (2005) 678-687.

36. R. Plummer, R.H. Wilson, H. Calvert, A.V. Boddy, M. Griffin, J. Sludden, M.J. Tilby, M. Eatock, D.G. Pearson, C.J. Ottley, Y. Matsumura, K. Kataoka, T. Nishiya. Br. J. Cancer 104 (2011) 593-598.

37. Y. Matsumura, K. Kataoka. Cancer Sci. 100 (2009) 572-579.

38. F. Koizumi, M. Kitagawa, T. Negishi, T. Onda, S. Matsumoto, T. Hamaguchi, Y. Matsumura. Cancer Res. 66 (2006) 10048-10056.

39. S. Danson, D. Ferry, V. Alakhov, J. Margison, D. Kerr, D. Jowle, M. Brampton, G. Halbert, M. Ranson. Br. J. Cancer 90 (2004) 2085-2091.

40. J.W. Valle, A. Armstrong, C. Newman, V. Alakhov, G. Pietrzynski, J. Brewer, S. Campbell, P. Corrie, E.K. Rowinsky, M. Ranson. Investig. New Drugs 29 (2011) 1029-1037.

41. Y. Matsumura, T. Hamaguchi, T. Ura, K. Muro, Y. Yamada, Y. Shimada, K. Shirao, T. Okusaka, H. Ueno, M. Ikeda, N. Watanabe. Br. J. Cancer 91 (2004) 1775-1781.

42. S. Mignani, S. El Kazzouli, M. Bousmina, J.-P. Majoral. Adv. Drug Deliv. Rev. 65 (2013) 1316-1330.

43. S. Jana, A. Gandhi, K.K. Sen, S.K. Basu. Am. J. Pharm. Tech. Res. 2 (2012) 32-55.

44. B.K. Nanjwade, H.M. Bechra, G.K. Derkar, F.V. Manvi, V.K. Nanjwade. Eur. J. Pharm. Sci. 38 (2009) 185-196.

45. T. Garg, O. Singh, S. Arora, R. Murthy. Int. J. Pharm. Sci. Rev. Res. 7 (2011) 211-220. 
46. D.A. Tomalia. Aldrichimica Acta 37 (2004) 39-57.

47. S.H. Medina, M.E. El-Sayed. Chem. Rev. 109 (2009) 3141-3157.

48. S. Svenson, R.K. Prud'homme, Multifunctional Nanoparticles for Drug Delivery Applications: Imaging, Targeting, and Delivery, Springer, New York, USA, 2012, pp. 1-365.

49. T.M. Allen, P.R. Cullis. Adv. Drug Deliv. Rev. 65 (2013) 36-48.

50. R. Michel, M. Gradzielski. Int. J. Mol. Sci. 13 (2012) 11610-11642.

51. H. Pinto-Alphandary, A. Andremont, P. Couvreur. Int. J. Antimicrob. Agents 13 (2000) 155-168.

52. A. Akbarzadeh, R. Rezaei-Sadabady, S. Davaran, S.W. Joo, N. Zarghami, Y. Hanifehpour, M. Samiei, M. Kouhi, K. Nejati-Koshki. Nanoscale Res. Lett. 8 (2013) 102-111.

53. G.U. Ruiz-Esparza, J.H. Flores-Arredondo, V. Segura-Ibarra, G. Torre-Amione, M. Ferrari, E. Blanco, R.E. Serda. Int. J. Nanomedicine 8 (2013) 629-640.

54. J. Du, J. Jin, M. Yan, Y. Lu. Curr. Drug Metab. 13 (2012) 82-92.

55. P. Kallinteri, S.G. Antimisiaris, D. Karnabatidis, C. Kalogeropoulou, I. Tsota, D. Siablis. Biomaterials 23 (2002) 4819-4826.

56. $\quad$ S.L. Gosangari, K.L. Watkin. Pharm. Dev. Technol. 17 (2012) 103-109.

57. A. Wagner, M. Platzgummer, G. Kreismayr, H. Quendler, G. Stiegler, B. Ferko, G. Vecera, K. Vorauer-Uhl, H. Katinger. J. Liposome Res. 16 (2006) 311-319.

58. J. Gubernator. Expert Opin. Drug Deliv. 8 (2011) 565-580.

59. Y. Fan, Q. Zhang. Asian J. Pharm. Sci. 8 (2013) 81-87.

60. R.H. Müller, K. Mäder, S. Gohla. Eur. J. Pharm. Biopharm. 50 (2000) 161-177.

61. K. Westesen. Colloid Polym. Sci. 278 (2000) 608-618.

62. R.H. Müller, M. Radtke, S.A. Wissing. Adv. Drug Deliv. Rev. 54 (2002) S131-S155.

63. S.A. Wissing, R.H. Müller. Int. J. Pharm. 242 (2002) 377-379.

64. S.A. Wissing, R.H. Müller. Eur. J. Pharm. Biopharm. 56 (2003) 67-72.

65. M.A. Videira, M.F. Botelho, A.C. Santos, L.F. Gouveia, J.J. Pedroso de Lima, A.J. Almeida. J. Drug Target. 10 (2002) 607-613.

66. J. Araújo, E. Gonzalez, M.A. Egea, M.L. Garcia, E.B. Souto. Nanomed. Nanotechnol. 5 (2009) 394-401.

67. C. Rudolph, U. Schillinger, A. Ortiz, K. Tabatt, C. Plank, R.H. Müller, J. Rosenecker. Pharm. Res. 21 (2004) 1662-1669.

68. I.P. Kaur, R. Bhandari, S. Bhandari, V. Kakkar. J. Control. Release. 127 (2008) 97-109.

69. M.A. Schubert, C.C. Müller-Goymann. Eur. J. Pharm. Biopharm. 55 (2003) 125-131.

70. F.Q. Hu, H. Yuan, H.H. Zhang, M. Fang. Int. J. Pharm. 239 (2002) 121-128.

71. $\quad$ W. Mehnert, K. Mäder. Adv. Drug Deliv. Rev. 47 (2001) 165-196.

72. A. Lippacher, R.H. Müller, K. Mäder. Int. J. Pharm. 196 (2000) 227-230.

73. T. Eldem, P. Speiser, A. Hincal. Pharm. Res. 8 (1991) 47-54.

74. $\quad$ L. Vigderman, E.R. Zubarev. Adv. Drug Deliv. Rev. 65 (2013) 663-676.

75. S. Chandra, K.C. Barick, D. Bahadur. Adv. Drug Deliv. Rev. 63 (2011) 1267-1281.

76. T. Tsuji, H. Yoshitomi, J. Usukura. Microscopy (Oxf.) 62 (2013) 341-352.

77. A. Höcherl, M. Dass, K. Landfester, V. Mailänder, A. Musyanovych. Macromol. Biosci. 12 (2012) 454-464. 
78. A. Musyanovych, J. Dausend, M. Dass, P. Walther, V. Mailänder, K. Landfester. Acta Biomater. 7 (2011) 4160-4168.

79. L. Tao, W. Hu, Y. Liu, G. Huang, B.D. Sumer, J. Gao. Exp. Biol. Med. 236 (2011) 20-29.

80. S.A. Kulkarni, S.-S. Feng. Pharm. Res. 30 (2013) 2512-2522.

81. S. Bhattacharjee, D. Ershov, K. Fytianos, J. van der Gucht, G.M. Alink, I.M.C.M. Rietjens, A.T.M. Marcelis, H. Zuilhof. Part Fibre Toxicol. 9 (2012).

82. A. Panariti, G. Miserocchi, I. Rivolta. Nanotechnol. Sci. Appl. 5 (2012)87-100.

83. M.P. Desai, V. Labhasetwar, E. Walter, R.J. Levy, G.L. Amidon. Pharm. Res. 14 (1997) 1568-1573.

84. T. Akagi, F. Shima, M. Akashi. Biomaterials 32 (2011) 4959-4967.

85. A. Gabizon, D. Papahadjopoulos. Proc. Natl. Acad. Sci. 85 (1988) 6949-6953.

86. L.M. Kaminskas, B.J. Boyd, C.J. Porter. Nanomedicine 6 (2011) 1063-1084.

87. N. Kamaly, Z. Xiao, P.M. Valencia, A.F. Radovic-Moreno, O.C. Farokhzad. Chem. Soc. Rev. 41 (2012) 2971-3010.

88. M. Gaumet, A. Vargas, R. Gurny, F. Delie. Eur. J. Pharm. Biopharm. 69 (2008) 1-9.

89. V.A. Hackley, J.D. Clogston, Characterization of Nanoparticles Intended for Drug Delivery, Humana Press, Totowa, USA, 2011, pp. 35-52.

90. X. Dong, C.A. Mattingly, M. Tseng, M. Cho, V.R. Adams, R.J. Mumper. Eur. J. Pharm. Biopharm. 72 (2009) 9-17.

91. T.M. Allen, A. Chonn. FEBS Lett. 223 (1987) 42-46.

92. J. Jiang, G. Oberdörster, P. Biswas. J. Nanoparticle Res. 11 (2009) 77-89.

93. M. Leroueil-Le Verger, L. Fluckiger, Y.-I. Kim, M. Hoffman, P. Maincent. Eur. J. Pharm. Biopharm. 46 (1998) 137-143.

94. R. Gref, P. Quellec, A. Sanchez, P. Calvo, E. Dellacherie, M.J. Alonso. Eur. J. Pharm. Biopharm. 51 (2001) 111-118.

95. J.D. Clogston, A.K. Patri, Characterization of Nanoparticles Intended for Drug Delivery, Humana Press, Totowa, USA, 2011, pp. 63-70.

96. H. Ali, G. Kilic, K. Vincent, M. Motamedi, E. Rytting. Ther. Deliv. 4 (2013) 161-175.

97. H. Drexler, H. Greim, R. Snyder, The MAK-Collection for Occupational Health and Safety, Wiley-VCH, Weinheim, Germany, 2010, pp. 1-349.

98. M.M. Arnold, E.M. Gorman, L.J. Schieber, E.J. Munson, C. Berkland. J. Control. Release 121 (2007) 100-109.

99. G. Vilar, J. Tulla-Puche, F. Albericio. Curr. Drug Deliv. 9 (2012) 367-394.

100. X.-Q. Wang, Q. Zhang. Eur. J. Pharm. Biopharm. 82 (2012) 219-229.

101. R. de la Rica, D. Aili, M.M. Stevens. Adv. Drug Deliv. Rev. 64 (2012) 967-978.

102. Y.L. Colson, M.W. Grinstaff. Adv. Mater. 24 (2012) 3878-3886.

103. W.B. Liechty, D.R. Kryscio, B.V. Slaughter, N.A. Peppas. Annu. Rev. Chem. Biomol. Eng. 1 (2010) 149-173.

104. A.K. Mohammad, J.J. Reineke. Mol. Pharm. 10 (2013) 2183-2189.

105. Y.-M. Tsai, W.-L. Chang-Liao, C.-F. Chien, L.-C. Lin, T.-H. Tsai. Int. J. Nanomedicine 7 (2012) 2957-2966.

106. J.B. Dressman, G.L. Amidon, C. Reppas, V.P. Shah. Pharm. Res. 15 (1998) 11-22.

107. D. Bhadra, S. Bhadra, S. Jain, N.K. Jain. Int. J. Pharm. 257 (2003) 111-124.

108. J. Siepmann, N.A. Peppas. Adv. Drug Deliv. Rev. 48 (2001) 139-157.

109. M.J. Hollamby. Phys. Chem. Chem. Phys. 15 (2013) 10566-10579. 
110. S. Mahabir, W. Wan, J. Katsaras, M.-P. Nieh. J. Phys. Chem. B 114 (2010) 5729-5735.

111. S. Mahabir, D. Small, M. Li, W. Wan, N. Kučerka, K. Littrell, J. Katsaras. Biochim. Biophys. Acta 1828 (2013) 1025-1035.

112. R. Lund, L. Willner, D. Richter, P. Lindner, T. Narayanan. ACS Macro Lett. 2 (2013) 1082-1087.

113. J. Chen, W.T. Dai, Z.M. He, L. Gao, X. Huang, J.M. Gong, H.Y. Xing, W.D. Chen. Indian J. Pharm. Sci. 75 (2013) 178-184.

114. R. Das, E. Ali, S.B. Abd Hamid. Rev. Adv. Mater. Sci. 38(2) (2014).

115. K. Pagar, P. Vavia. Sci. Pharm. 81 (2013) 865-885.

116. S. Talam, S.R. Karumuri, N. Gunnam. ISRN Nanotechnol. 2012 (2012) 372505.

117. S. Bykkam, M. Ahmadipour, S. Narisngam, V.R. Kalagadda, S.C. Chidurala. Adv. Nanoparticles 4(1) (2015) 53545.

118. P. Gill, T.T. Moghadam, B. Ranjbar. J. Biomol. Tech. 21(4) (2010) 167-193.

119. M.H. Sadr, H. Nabipour. J. Nanostructure Chem. 3 (2013) 1-6.

120. R. Sierra-Ávila, M. Pérez-Alvarez, G. Cadenas-Pliego, C.A. Ávila-Orta, R. Betancourt-Galindo, E. Jiménez-Regalado, R.M. Jiménez-Barrera, J.G. Martínez-Colunga. J. Nanomater. 2014 (2014) 361791.

121. J.J. Pillai, A.K.T. Thulasidasan, R.J. Anto, N.C. Devika, N. Ashwanikumar, G.V. Kumar. RSC Adv. 5 (2015) 25518-25524.

122. V.D. Wagh, D.U. Apar. J. Nanotechnol. 2014 (2014) 683153.

123. P. Mróz, S. Białas, M. Mucha, H. Kaczmarek. Thermochim. Acta 573 (2013) 186-192.

124. G.S. El-Feky, M.H. El-Rafie, M.A. El-Sheikh, M.E. El-Naggar, A. Hebeish. J. Nanomed. Nanotechnol. 6 (2015) 254.

125. F. Huth, M. Schnell, J. Wittborn, N. Ocelic, R. Hillenbrand. Nat. Mater. 10 (2011) 352-356.

126. F. Huth, A. Govyadinov, S. Amarie, W. Nuansing, F. Keilmann, R. Hillenbrand. Nano Lett. 12 (2012) 3973-3978.

127. E. Rytting, M. Bur, R. Cartier, T. Bouyssou, X. Wang, M. Krüger, C.-M. Lehr, T. Kissel. J. Control. Release 141 (2010) 101-107. 